Евгения Чикова

\title{
ПРОШЛОЕ, НАСТОЯЩЕЕ И БУДУЩЕЕ СОЦИАЛЬНЫХ ИНВЕСТИЦИЙ
}

\author{
Hemerijck A. (2017) The Uses of Social Investment. Oxford: \\ Oxford University Press. 475 p. ISBN: 978-0-19-879049-5
}

DOI: $10.17323 / 727-0634-2021-19-1-177-182$

Книга под редакцией Антона Химерийка «Польза социальных инвестиций» является продолжением работы «Трансформация государств всеобщего благосостояния» (Hemerijck 2013), в которой анализу подвергались волны реформ, прокатившихся по Европе в последние два десятилетия. Его соавторами выступили 49 специалистов в области экономики, юриспруденции, политологии и социологии, исследователи государства всеобщего благосостояния, развернувшие на страницах коллективной монографии дискуссию о прошлом и будущем социальных инвестиций как инструмента развития общества. Социальные инвестиции рассматриваются в книге как всеобъемлющая стратегия развития, использования и защиты человеческого капитала для преодоления рисков конкурентной экономики. В практическом отношении стратегия выражается в разнообразных программах и мерах поддержки граждан с раннего детства до поздней старости. Одновременно в рамках социального инвестирования выделяются три направления работы: упрощение «потоков» современного рынка труда и гендерных переходов внутри него; повышение качества «запаса» человеческого капитала и сопряженных с этим общественных возможностей; поддержание надежных универсальных сетей социальной защиты и экономической стабилизации как «буфера» безопасности в стареющих сообществах.

Парадигму социального инвестирования, как отмечается во Введении, предваряли кейнсианско-бевериджская и неолиберальная модели социального государства. Первая из них ориентировалась на поддержание полной занятости мужчин и всеобщее социальное обеспечение в случае безработицы, болезни, инвалидности и бедности в старости. Но она же фактически ставила детей и женщин в полную зависимость от возможностей трудоустройства и заработной платы мужчин. Вторая пыталась смягчить жесткие условия на рынке труда за счет политики перераспределения доходов и расширения занятости в государственном секторе, что сводило на нет частную экономическую инициативу, приводило к снижению

Евгения Викторовна Чикова - ст. преподаватель, кафедра социальной работы, Уральский федеральный университет имени первого Президента России Б.Н. Ельцина, Екатеринбург, Россия. Электронная почта: putilova.evgenia@urfu.ru 
предложения рабочей силы и прежде всего квалифицированных кадров, большему сокращению чистой заработной платы, повышению безработицы среди престарелых, молодежи и низкоквалифицированных работников. «Большой компромисс» между равенством и эффективностью к концу XX в. вел страны Евросоюза к стагнации (Okun 1975).

Переход от политики расходов к политике социальных инвестиций был продиктован необходимостью ослабления контроля рынка труда и сокращения расходов в социальной сфере после кризиса, пережитого государствами всеобщего благосостояния. Преимущества политики социальных инвестиций, по мнению аналитиков, заключались в том, что конечной целью становилась не столько полная занятость, сколько высокий уровень занятости и повышение качества рабочей силы, необходимые для того, чтобы противодействовать передаче социального неуспеха из поколения в поколение. В то же время обеспечение и расширение спектра услуг в сфере образования, поддержки семьи, здравоохранения и жилья в рамках политики социальных инвестиций рассматривались как тактическая предпосылка для устойчивого уровня занятости, экономического роста и благосостояния (Esping-Andersen et al. 2002).

Критический анализ границ эффективности социальных инвестиций, представленный во второй главе «Пределы социальных инвестиций», обращен к ключевым рискам политики социальных инвестиций. Отмечается, что в странах с низкими темпами роста и, соответственно, низкими налогами она может дать обратный экономический эффект. Социальные инвестиции не могут полноценно заменить и институт социальной защиты в силу своей узкой целевой направленности. Кроме того, последовательное проведение политики социального инвестирования может привести к разделению клиентов на «достойных» (дети, семьи) и «недостойных» (пожилые, инвалиды). Одновременно обращает на себя внимание косвенная контрпродуктивность социальных инвестиций в сфере гендерного равенства за счет разделения «женской» занятости на более продуктивную (женщина-работник) и менее продуктивную (женщина-опекун). В ряде случаев существует риск появления эффекта Матфея, связанного с укреплением неравномерного распределения преимуществ между благополучателями. В заключении раздела внимание концентрируется на невозможности проведения полноценной политики социальных инвестиций в условиях жесткой бюджетной экономии.

В третьей главе «Эндаумент и наращивание социальных инвестиций» акцент сделан на проблеме увеличения объема социальных инвестиций перед лицом структурных изменений и кризиса. Прежде всего, отмечается высокий приоритет социальных инвестиций, вкладываемых в сферу дошкольного, школьного и университетского образования, что в перспективе обеспечивает равновесие рынка труда при общем росте занятости, снижение уровня относительной бедности и сокращение неравенства. Активная 
политика социальных инвестиций становится результатом не только государственной политики, но и частной инициативы, и с методологической точки зрения обусловлена стремлением не к социальной справедливости, но к личному и общественному прогрессу.

Различные способы оценки «отдачи» от социальных инвестиций рассматриваются в четвертой главе «Оценка социальных инвестиций»: речь идет об измерении разработанных показателей эффективности политики. Оценивается возможный сдвиг в режиме политики на основании «нулевых» входных данных. Измеряются показатели отдельных компонентов политики социальных инвестиций. В качестве примера в одной из глав приводится измерение социальных инвестиций как производительного фактора экономики через подсчет повышения качества «акций» участников рынка труда пропорционально объему принятых инвестиционных мер. При этом оценка существенно осложняется за счет ряда факторов: многогранности толкования термина «социальные инвестиции»; многообразия результатов социальных инвестиций с точки зрения различных аспектов благосостояния для различных групп граждан; многообразия институтов, участвующих в осуществлении политики социальных инвестиций; «отсроченности» результатов политики социальных инвестиций во времени. Последний пункт может оказывать сильное влияние на выбор поддерживаемых государством отраслей или проектов. В одном случае может быть выбран проект с краткосрочными экономическими дивидендами в ущерб политическим и социальным результатам в будущем, в другом-во главу встанут долгосрочные социальные и политические дивиденды.

Наиболее интересным представляется материал пятой главы «Сравнительный опыт социальных инвестиций», в которой выделяются различные изменения в политике социального инвестирования и разнообразные стратегии в системах социального обеспечения стран Европы, Азии и Америки. Глава начинается с описания существенного вклада таких организаций, как Всемирный банк и Организация экономического развития и сотрудничества, в пропаганду социального инвестирования. Затем приводится пример государств Скандинавского полуострова, который, однако, не может считаться образцовым из-за разбалансировки «буферов» социальной защиты, приводящих к сокращению пособий для бедных и обездоленных, при расширении спектра услуг, которыми пользуется средний класс. В Германии прогрессивная трансформация семейной политики в русле парадигмы социального инвестирования удачно дополнилась реформами Харца, которые выразились в мерах по увеличению гибкости рынка труда и роста количества рабочих мест за счет атипичной занятости, изменения системы помощи безработным. Нидерланды, которые проводили политику социальных инвестиций с 1990-х гг., вынуждены были приостановить ее из-за резкого сокращения средств бюджета вследствие кризиса финансового рынка. В Ирландии же, в отличие от Нидерландов, 
кризис вызвал массовую финансовую консолидацию, которая привела к реформе государственных служб в русле социального инвестирования и развитию сферы образования и ухода за детьми в качестве помощи родителям-одиночкам. В Квебеке социальные инвестиции в течение значительного времени были включены в повестку дня, что находило отражение в проведении реформ, направленных на развитие дошкольного образования и поощрение участия на рынке труда всех лиц трудоспособного возраста. Тем не менее успех данных реформ был ограниченным в силу того, что одновременно реструктуризации подвергся региональный бюджет, а другие социальные программы были сокращены. В Азии в деле продвижения социальных инвестиций примером стала Южная Корея, которая задействовала социальную инвестиционную стратегию для решения проблем женской занятости и низкой рождаемости. Определенные результаты были достигнуты и в странах Латинской Америки, где за счет условных денежных переводов была повышена посещаемость школ, учреждений здравоохранения и, соответственно, возрос уровень человеческого капитала. Однако проблемой остается перераспределение объема социальных инвестиций в пользу молодежи для слома цикла межпоколенческого наследования бедности. Завершает главу описание неудачного опыта Италии по внедрению политики социальных инвестиций, прежде всего из-за отсутствия корреляции в проведении политики ухода за детьми и занятости женщин, а также ограниченного финансирования, институциональной инертности и значительной региональной дифференциации.

Главы шестая «Пропаганда социальных инвестиций в ЕС» и седьмая «Политика социальных инвестиций» посвящены анализу роли ЕС в продвижении социальных инвестиций и вопросам легитимации последних. В первом случае выявляется противоречие между декларируемой и реально проводимой политикой: с одной стороны, рекомендации Еврокомиссии по проведению реформ в русле социального инвестирования получают все государства-члены, с другой стороны, большинству из них навязывается режим жесткой экономии, который препятствует реальному проведению реформ соответствующего характера. Таким образом, проводить политику социальных инвестиций могут позволить себе только экономически сильные члены Евросоюза, а мы можем наблюдать эффект Матфея в политическом измерении. Что же касается легитимации реформ социальных инвестиций, подчеркивается, что она напрямую зависит от существующего наследия социальной политики, а также коалиционной согласованности интересов бизнеса, среднего и рабочего класса. По мнению авторов, проблемой для легитимации политики социальных инвестиций является позиция миллениалов, которые не хотят нести двойную налоговую нагрузку- на социальное обеспечение и социальное инвестирование, не готовы мириться с сокращением расходов на социальное обеспечение и хотели бы сохранить свои «социальные привилегии» путем отстранения от них мигрантов и других «посторонних лиц». 
В завершающей главе «Использование доступных социальных инвестиций» Химерийк заключает, что у политики социальных инвестиций, остановленной натиском глобального финансового кризиса, еще есть шанс. Но для эффективного ее проведения необходимо снять единообразные фискальные правила для всех государств-членов Евросоюза, установленные Маастрихтским договором, чтобы они смогли перераспределять бюджетные средства в пользу социальных инвестиций, не опасаясь штрафных санкций. Это, в свою очередь, позволит разыграть козырь повышения женской (и материнской) занятости и ослабить давление в части сдерживания расходов на здравоохранение и пенсионное обеспечение, поскольку увеличится количество активных участников рынка труда и налогоплательщиков.

Книга, с одной стороны является хорошо структурированным европоцентристским обзором истории, программ и результатов политики социальных инвестиций, с другой-выступает интересной дискуссионной площадкой для обсуждения новых подходов к развитию государства всеобщего благосостояния. Выводы, предлагаемые авторским коллективом монографии, не теряют своей актуальности, что находит подтверждение в более поздних исследованиях (Busemeyer et al. 2020; Careja et al. 2020; Baines et al. 2019). Представляется, что эта работа может рассматриваться в качестве вводной в изучении темы социальных инвестиций. В то же время ее материал может быть органично дополнен дебатами о сущности понятия «социальные инвестиции» в рамках академического и практического использования термина в сфере менеджмента государственного сектора и НКО, дискуссией о проблемах и различиях проведения политики социальных инвестиций в странах Глобального Севера и Глобального Юга, в ряде стран с развивающейся экономикой (БРИКС), о роли международных организаций в продвижении социальных инвестиций (см. Midgley et al. 2017).

\section{Выражение признательности}

Рецензия подготовлена при поддержке РНФ, проект № 19-18-00246 «Вызовы трансформации социального государства в России: институциональные изменения, социальное инвестирование, цифровизация социальных услуг», реализуемый в СПбГУ. 
Evgeniya Chikova

THE PAST, PRESENT AND FUTURE OF SOCIAL INVESTMENT

Hemerijck A. (2017) The Uses of Social Investment. Oxford: Oxford University

Press. 475 p. ISBN: 978-0-19-879049-5

DOI: $10.17323 / 727-0634-2021-19-1-177-182$

\section{Acknowledgments}

This article was carried out with support of the Russian Science Foundation (RSF) according to scientific project no. 19-18-00246 'Challenges of Transformation of the Welfare State in Russia: Institutional Changes, Social Investment, Digitalization of Social Services,' implemented at Saint Petersburg State University.

\section{References}

Baines S., Bassi A., Csoba J., Sipos F. (2019) Implementing Innovative Social Investment: Strategic Lessons from Europe. Bristol: Policy Press.

Busemeyer M. R., Porte de la. C., Garritzmann J.L. Pavolini E. (2020) The Future of the Social Investment State: Politics, Policies and Outcomes. New York: Routledge.

Careja R., Emmenegger P., Giger N. (2020) The European Social Model under Pressure. Wiesbaden: Springer.

Esping-Andersen G., Gallie D., Hemerijck A., Myles J. (2002) Why We Need a New Welfare State. Oxford: Oxford University Press.

Hemerijck A. (2013) Changing Welfare States. Oxford: Oxford University Press.

Okun A.M. (1975) Equality and Efficiency: The Big Trade Off. Washington, DC: The Brookings Institution.

Midgley J, Dahl E., Conley Wright A. (2017) Social Investment and Social Welfare. International and Critical Perspectives. Northampton: Edward Elgar Publishing.

Evgeniya V. Chikova - senior lecturer, department of social work, Ural Federal University named after the first President of Russia B. N. Yeltsin, Ekaterinburg, Russian Federation. Email: putilova.evgenia@urfu.ru 